\title{
A Randomized Controlled Trial on the Effect of Montelukast on Sputum Eosinophil Cationic Protein in Children with Corticosteroid- Dependent Asthma
}

\author{
ELKE STRAUCH, OLAF MOSKE, SANDRA THOMA, KARIN STORM VAN'S GRAVESANDE, \\ GABRIELE IHORST, MATTHIAS BRANDIS, AND JOACHIM KUEHR
}

University Children's Hospital, D-79106 Freiburg, Germany

ABSTRACT

\begin{abstract}
Previous adult studies demonstrated the clinical efficacy of an additional treatment with leukotriene receptor antagonists on steroid-dependent asthma, but there is little knowledge about anti-inflammatory add-on effects within the lung. In this study, we hypothesized that steroid-treated children exhibit a decrease in bronchial inflammation in induced sputum under additional treatment with montelukast. Twenty-five asthmatic children aged 6 to $14 \mathrm{y}$, who had been taking inhaled corticosteroids (400-800 $\mu \mathrm{g} / \mathrm{d}$ budesonide) regularly for at least $12 \mathrm{wk}$, were randomized to receive additional treatment with either montelukast $(5 \mathrm{mg}$ orally, once daily) or placebo over a 4-wk period. As primary efficacy variable, eosinophil cationic protein (ECP) in induced sputum as direct measurement of bronchial inflammation was assessed before and after treatment. To assure a baseline level of inflammation, an ECP concentration above $100 \mu \mathrm{g} / \mathrm{L}$ was required. Sputum eosinophil count, concentration of exhaled nitric oxide, urinary excretion of eosinophil protein $\mathrm{X}$, and quality-oflife items were considered as secondary outcome variables. After treatment with montelukast, ECP in sputum was significantly reduced (montelukast: median $-975 \mu \mathrm{g} / \mathrm{L}$ [5 to $95 \%$ confidence interval: -4295 to $583 \mu \mathrm{g} / \mathrm{L}]$; placebo: $561 \mu \mathrm{g} / \mathrm{L}[-1335$ to
\end{abstract}

$3320 \mu \mathrm{g} / \mathrm{L}] ; p<0.01)$ and the quality-of-life score had significantly improved $(p<0.05)$ compared with placebo. Partly explained by low baseline levels, no statistically significant change in concentration of exhaled nitric oxide $(p>0.05)$, urinary excretion of eosinophil protein $\mathrm{X}(p>0.05)$, or eosinophil count $(p>0.05)$ was found. In conclusion, add-on treatment with montelukast can suppress sputum ECP in children with steroid-dependent asthma, while at the same time an improvement in quality of life items occurs. (Pediatr Res 54: 198-203, 2003)
Abbreviations
LTRA, leukotriene receptor antagonist
Cys-LT, cysteinyl leukotriene
ECP, eosinophil cationic protein
UEPX, urinary excretion of eosinophil protein $\mathrm{X}$
FeNO, exhaled nitric oxide
QOL, quality of life
FVC, forced vital capacity
$\mathbf{F E V}$, forced expiratory volume in the first second

Asthma is the most common chronic disease in children and results in a considerable burden in the child's daily life (1). Inhaled glucocorticosteroids are the most potent antiinflammatory drugs currently available and are the first-line therapy in patients with chronic asthma (2). However, longterm side effects of inhaled corticosteroids in young children cannot be fully excluded (3). Moreover, several studies have shown a persistent inflammation in steroid-treated asthmatics (4-7), and it has been postulated that inadequate treatment of airway inflammation may lead to irreversible changes in airway function (8). LTRA such as zafirlukast, pranlukast, and montelukast are able to reduce effects of Cys-LT (leukotriene

Received January 18, 2002; accepted November 26, 2002.

Correspondence: Joachim Kuehr, Mathildenstraße 1, D-79106 Freiburg, Germany; e-mail: kuehr@kikli.ukl.uni-freiburg.de
C4, D4, and E4) and are increasingly used as additional anti-inflammatory drugs. The local pulmonary efficacy of zafirlukast was demonstrated in bronchoscopy-based studies $(9,10)$. Recently, it has been shown that pranlukast is able to reduce bronchial inflammation assessed by sputum markers in asthmatic adults (11).

Montelukast, although frequently used for children, has been evaluated on the basis of indirect measurements (e.g. eosinophils in serum, FeNO) (12-15) but not on the basis of direct measurements (e.g. ECP in bronchial lavage or sputum). As montelukast is particularly indicated as add-on therapy when corticosteroids have not been sufficiently effective and a steroid-sparing agent is required, we hypothesized that montelukast is able to reduce eosinophilic inflammation even under pretreatment with inhaled steroids. Therefore, we performed a 
randomized, placebo-controlled parallel-group trial to quantify the additional benefit of $5 \mathrm{mg}$ montelukast once daily on sputum ECP and enrolled asthmatic children who had ECP levels above $100 \mu \mathrm{g} / \mathrm{L}$ despite therapy with budesonide at daily doses of between 400 and $800 \mu \mathrm{g}$.

\section{METHODS}

Population. Of 36 children visiting the outpatient department of the University Children's Hospital and fulfilling the screening criteria (having mild to moderate asthma based on the criteria of the American Thoracic Society (16) and taking inhaled corticosteroids at doses between 200 and $400 \mu \mathrm{g}$ budesonide twice daily regularly for at least $12 \mathrm{wk}$; age 6-14 y), 25 children had a sputum ECP of $100 \mu \mathrm{g} / \mathrm{L}$ or higher before treatment. As could be assumed from earlier testing, all children were allergic to common inhalant allergens and had been free of respiratory infections or an asthma exacerbation for at least 4 wk before enrolment. Patients using systemic corticosteroids, cromolyn sodium, nedocromil, anticholinergics, theophyline, antihistamines, or an antileukotriene medication, such as montelukast, were excluded. The use of a $\beta_{2}$-agonist on demand was allowed throughout, but patients were not allowed to change their dose of inhaled budesonide during the study. The study was approved by the ethics committee of the University Hospital and informed written consent was obtained for each patient.

Study design. A double-blind, placebo-controlled, randomized design was used (Fig. 1). The study was carried out between April and December and consisted of a run-in phase of 7 to $10 \mathrm{~d}$, which was immediately followed by a 4-wk treatment phase. During the run-in period, the stability of asthma and the compliance of the subjects were checked (difference between $\mathrm{FEV}_{1}$ at the first two visits $<10 \%$; the daily diary protocol had to be completed for 6 out of the first $7 \mathrm{~d}$ during the run-in period). Compliance with treatment was assessed by the completion of the daily diary protocol and by the collection and counting of the study medication at the end of the study. At the end of this period and before study treatment, a baseline sputum induction was performed to determine bronchial inflammation. Only if bronchial inflammation could be demon- strated on the basis of a sputum ECP level $>100 \mu \mathrm{g} / \mathrm{L}$ the patient was randomly assigned to receive a daily single dose of either montelukast (5 $\mathrm{mg}$ chewable tablet at bedtime (17)) or placebo (Rottendorf Pharma GmbH, Ennigerloh, Germany), both of which were identical in appearance and taste, during a 4-wk course. The study physicians were kept blind throughout the trial and the patients received the same treatment apart from the experimental treatment. The primary outcome variable was the ECP concentration in induced sputum. Secondary outcome variables were sputum eosinophil count, FeNO level, uEPX excretion, and QOL scores (18). The outcome measurements took place in the afternoon between 1300 and $1800 \mathrm{~h}$. Pulmonary function tests and a daily diary protocol (symptoms and use of $\beta_{2}$-agonists) were used.

Spirometry. All children underwent spirometry according to international guidelines (19). Two reproducible (difference between $\mathrm{FVC} \leq 5 \%$ ) flow volume curves were recorded by using a Masterscope version 4.0 (E. Jaeger, Würzburg, Germany). $\mathrm{FVC}$ and $\mathrm{FEV}_{1}$ were presented as a percentage of predicted value for each child (20).

Measurement of exhaled nitric oxide. FeNO was measured during a single breath exhalation by means of a computerized system for online recordings (Exhaled Breath Analyzer, Aerocrine AB, Stockholm, Sweden) as reported previously (5). Three vital capacity maneuvers were performed at 2-min intervals before sputum induction, and the mean of two reproducible readings (i.e. variation coefficient $<30 \%$ ) was used for analysis as calculation for median and $90 \%$ intervals.

Sputum induction. Sputum induction was performed as described by Pin et al. (21). Ten minutes after inhalation of 200 $\mu \mathrm{g}$ salbutamol, subjects inhaled hypertonic saline $(3,4$, and 5\%) via an ultrasonic nebulizer (Ultraneb 2000, De Villbiss, Somerset, PA, U.S.A.) with the output set at maximum (4.5 $\mathrm{mL} / \mathrm{min}$ ) for three consecutive periods of 10 min for each concentration. Lung function was recorded before the procedure and every 5 min during it. To collect sputum, subjects were asked to rinse their mouth, blow their nose, swallow water and then to expectorate the sputum onto a plastic Petri dish after the first 10-min period of inhalation and every $5 \mathrm{~min}$ thereafter. During the induction procedure, macroscopic char-

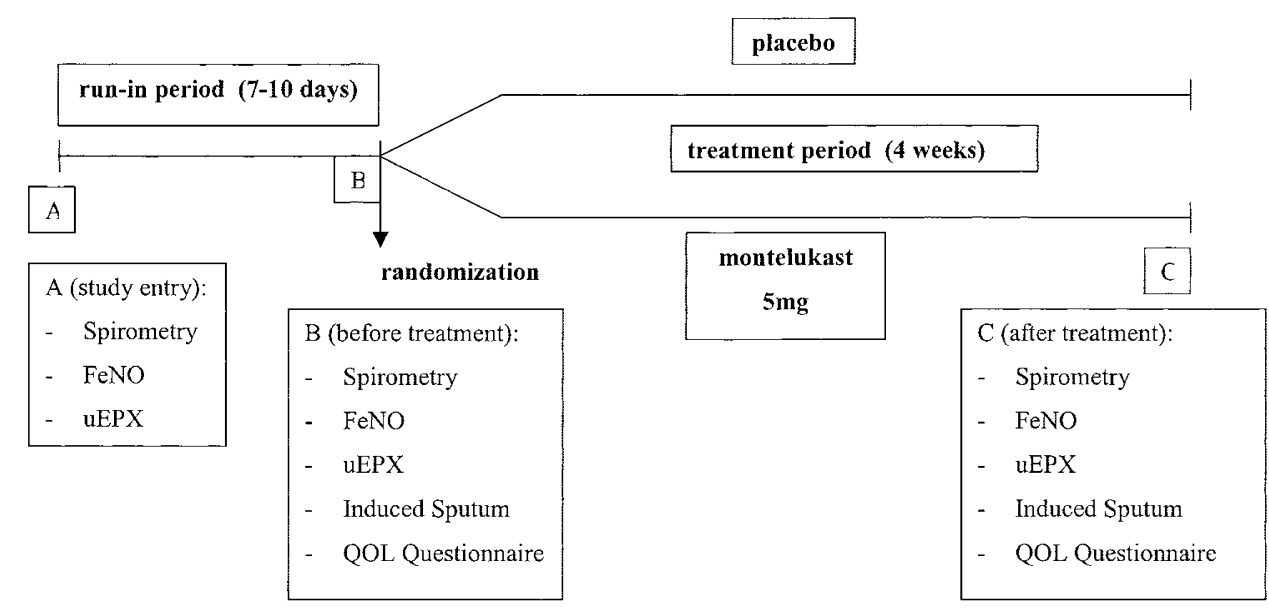

Figure 1. Study design. 
acteristics of the sputum were recorded and adequate plugs of sputum were separated from saliva and processed immediately after expectoration.

Sputum processing. Sputum processing was performed as previously described (5). Eosinophil counts were carried out by two experienced investigators on cytospins stained with MayGrünwald-Giemsa, and at least 400 nonsquamous cells were counted (interobserver variability in eosinophil count: coefficient of variation 15\%). Eosinophil counts were expressed as percentage of all nonsquamous cells.

Analysis of sputum ECP and $\mathbf{E E P X}$. Using the Pharmacia CAP system (ECP FEIA, Pharmacia \& Upjohn, Freiburg, Germany), ECP was analyzed in the supernatants of the selected plugs. Two measurements were performed simultaneously. A single, nonselectively collected sample of urine was taken and immediately frozen at $-70^{\circ} \mathrm{C}$. Levels of uEPX were measured with a double antibody RIA (Pharmacia \& Upjohn, Freiburg, Germany). Measurement of urine creatinine was carried out by using the alkaline picrate method (Jaffé reaction) (22). Results of uEPX excretion were presented in micrograms per millimole creatinine.

Daily diary protocol. To evaluate the effect of montelukast on the improvement of daily symptoms, all children completed a diary protocol at home on a daily basis. The asthma-like symptoms wheezing, dyspnea, tightness of chest, and coughing and $\beta_{2}$-agonist use were evaluated.

QOL questionnaire. To evaluate the impact of asthma on the children's daily life, all subjects completed a standardized QOL questionnaire (18). The questionnaire included 23 items in three domains-activity (five items), symptoms (10 items), and emotional function (eight items). In the activity domain, three of the items were individualized. Response options for each item were on a seven-point scale, where 1 indicated maximum impairment and 7 indicated no impairment. Results were expressed as the mean score per item for each of the domains as well as for overall QOL. Patients were asked to recall impairments they had experienced since the previous study visit.

Statistical analysis. For descriptive purposes, we calculated median and fifth and $95^{\text {th }}$ percentiles. Comparisons between placebo and treatment group were carried out using Wilcoxon's two-sample test. Regarding the different parameters of asthma control, our analysis focused on the changes in these parameters achieved during the treatment period, i.e. we compared the level before and after treatment. Statistical analysis was made using the SAS package, version 6.12 (SAS Institute, Inc., Cary, NC, U.S.A.).

\section{RESULTS}

Out of 36 children, 10 had a negative screening (six children had an ECP $<100 \mu \mathrm{g} / \mathrm{L}$ at baseline, two children were not able to expectorate valuable sputum after inhalation of hypertonic saline, and two children had a $\mathrm{FEV}_{1}<65 \%$ and therefore sputum induction was not started). One child dropped out of the study during the treatment period because of an acute infection.

The individual clinical characteristics and the amount of inhaled budesonide used by each child are shown in Table 1 . At baseline, we found no significant differences between the montelukast and the placebo group regarding the outcome variables (ECP [ $p>0.05]$, eosinophil count [ $p>0.05]$, FeNO

Table 1. Characteristics of randomized patients at study entry

\begin{tabular}{|c|c|c|c|c|c|c|c|c|c|}
\hline $\begin{array}{l}\text { Patient } \\
\text { no. }\end{array}$ & Sex & Age (y) & $\begin{array}{c}\mathrm{FEV}_{1} \\
(\% \text { pred })\end{array}$ & $\begin{array}{c}\text { FVC }(\% \\
\text { pred })\end{array}$ & FeNO (ppb) & $\begin{array}{l}\text { Sputum ECP } \\
(\mu \mathrm{g} / \mathrm{L})\end{array}$ & $\begin{array}{l}\text { Sputum eosinophils } \\
(\%)\end{array}$ & $\begin{array}{c}\mathrm{uEPX} \\
(\mu \mathrm{g} / \mathrm{mmol} \text { creatinine })\end{array}$ & $\begin{array}{c}\text { Budesonide dose } \\
(\mu \mathrm{g} / \mathrm{d})\end{array}$ \\
\hline 1 & $\mathrm{M}$ & 7 & 90 & 94 & 42 & 2458 & 1.2 & 116 & 400 \\
\hline 2 & M & 10 & 98 & 106 & 6 & 273 & - & 30 & 400 \\
\hline 3 & M & 13 & 99 & 106 & 16 & 210 & 1.2 & 19 & 800 \\
\hline 4 & M & 10 & 100 & 97 & 37 & 132 & 1.4 & 33 & 400 \\
\hline 5 & M & 14 & 101 & 101 & 68 & 1540 & 1.0 & 57 & 800 \\
\hline 6 & M & 9 & 91 & 89 & 22 & 740 & 1.2 & 41 & 600 \\
\hline 7 & M & 11 & 104 & 110 & 30 & 1728 & 2.6 & 74 & 400 \\
\hline 8 & M & 10 & 108 & 109 & 78 & 770 & - & 94 & 400 \\
\hline 9 & M & 10 & 89 & 89 & 7 & 3750 & 2.4 & 67 & 600 \\
\hline 10 & M & 8 & 104 & 118 & 11 & 1890 & 1.6 & 41 & 400 \\
\hline 11 & M & 11 & 78 & 84 & - & 2178 & 2.0 & 25 & 600 \\
\hline 12 & M & 13 & 96 & 79 & 44 & 155 & 0.6 & 63 & 400 \\
\hline 13 & M & 7 & 107 & 107 & 20 & 688 & 1.2 & 280 & 400 \\
\hline 14 & M & 9 & 90 & 107 & 31 & 3540 & 4.2 & 103 & 800 \\
\hline 15 & M & 10 & 89 & 98 & 57 & 2210 & 1.8 & 60 & 400 \\
\hline 16 & M & 8 & 98 & 98 & 14 & 209 & 2.8 & 72 & 400 \\
\hline 17 & $\mathrm{~F}$ & 12 & 112 & 119 & 6 & 300 & 0.2 & 25 & 400 \\
\hline 18 & $\mathrm{~F}$ & 11 & 108 & 108 & 5 & 2038 & 1.2 & 36 & 400 \\
\hline 19 & $\mathrm{~F}$ & 8 & 90 & 105 & 89 & 4525 & 6.0 & 75 & 800 \\
\hline 20 & $\mathrm{~F}$ & 8 & 103 & 99 & 12 & 1200 & 5.0 & 64 & 400 \\
\hline 21 & $\mathrm{~F}$ & 10 & 70 & 79 & 24 & 4625 & 2.0 & 42 & 400 \\
\hline 22 & $\mathrm{~F}$ & 12 & 97 & 106 & 13 & 1040 & 1.6 & 14 & 400 \\
\hline 23 & $\mathrm{~F}$ & 10 & 105 & 122 & 6 & 118 & 1.2 & 125 & 400 \\
\hline 24 & $\mathrm{~F}$ & 11 & 116 & 105 & 100 & 156 & 9.0 & 52 & 400 \\
\hline 25 & $\mathrm{~F}$ & 8 & 81 & 88 & 10 & 1825 & 0.2 & 58 & 800 \\
\hline
\end{tabular}

M, male; F, female; \% pred, percentage of predicted value; ppb, parts per billion. 
$[p>0.05]$, uEPX $[p>0.05])$ and other relevant variables (pulmonary function, history of asthma-like symptoms, use of $\beta_{2}$-agonist; data not shown).

Compliance was good in all cases.

No patient reported an adverse event for the 4 wk of add-on treatment with montelukast. The concentration of sputum ECP showed a significantly stronger reduction in the montelukast group ( $p<0.01$; Table 2, Fig. 2). There was no significant change in the FeNO level, in the eosinophil count $(p>0.05$, Table 2), in the uEPX excretion $(p>0.05)$ and in $\operatorname{FEV}_{1}(p>$ $0.05)$. However, montelukast treatment resulted in a significant improvement in the overall QOL score $(p<0.05$; Table 3$)$ as well as in the domain "emotions" ( $p<0.05$; Table 3$)$. In our study, a negative correlation between ECP and QOL improvements was found (Spearman correlation coefficient $-0.47, p=$ 0.02 ). During the entire treatment and run-in period, patients in both groups reported in their daily diary protocol that they were symptom-free and had not used a $\beta_{2}$-agonist (data not shown).

\section{DISCUSSION}

This double-blind, placebo-controlled trial in young asthmatic patients under treatment with budesonide was able to show that additional therapy with montelukast over a 4-wk period results in a significant decrease in sputum ECP. Although there are several studies showing the efficacy of montelukast or zafirlukast in asthmatics, the role of LTRA in the stepwise management of asthma has not yet been fully established. As previous studies have shown that elevated Cys-LT levels in asthmatics are not affected by steroids $(23,24)$, it seemed reasonable to use LTRA to minimize the bronchoconstrictive and proinflammatory effects of Cys-LT. Antiinflammatory effects on peripheral eosinophil number $(15,25)$, on eosinophil count, and on sputum ECP $(11,26)$ were shown for LTRA administered as monotherapy. However, no randomized controlled trial was published using material from the lower airways to investigate the effect on eosinophil inflammation induced by LTRA as treatment in addition to pretreatment with inhaled corticosteroids.

Montelukast has been observed to improve measures of asthma control when compared with placebo $(12,13,15)$. The add-on therapy with montelukast in addition to inhaled budesonide $(400 \mu \mathrm{g} / \mathrm{d})$ was shown to improve $\mathrm{FEV}_{1}(p<0.001)$

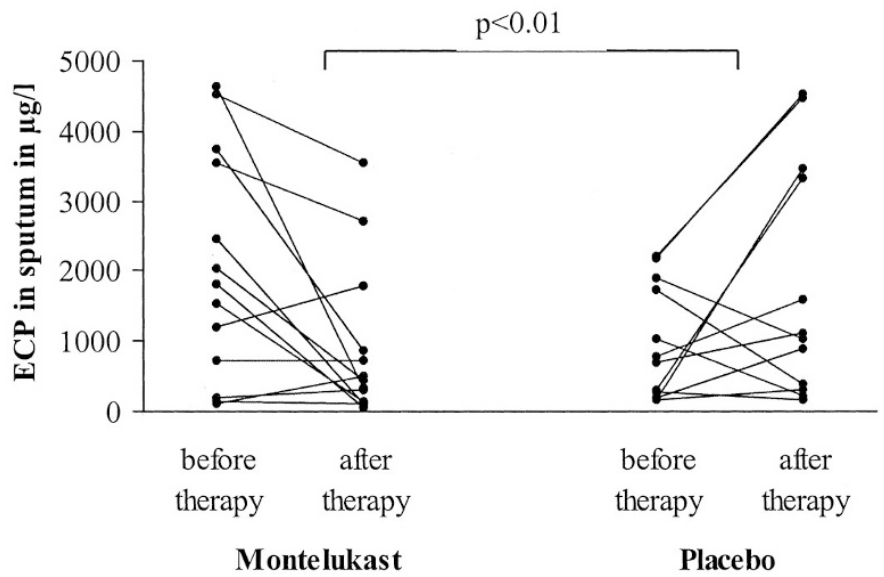

Figure 2. Individual results of $\mathrm{ECP}(\mu \mathrm{g} / \mathrm{L})$ before and after the 4-wk treatment with montelukast or placebo.

(14). These findings are in accordance with our results on ECP in induced sputum. Sputum ECP was found to be a reproducible and valid marker of eosinophilic activation (27) and might be in a position to display the inflammatory process even when eosinophils are not visible because of degranulation. In the placebo group, ECP increased, whereas the number of eosinophils decreased (Table 2), which is most likely because of eosinophil degranulation. This finding reinforces the importance of measuring ECP as a more reliable marker of inflammation in induced sputum. Based on previous experiences in a comparable population (5), patients with ECP levels $>100$ $\mu \mathrm{g} / \mathrm{L}$ representing eosinophil bronchial inflammation were enrolled. In this study, the principle that montelukast is effective in the case of ongoing eosinophil inflammation despite pretreatment with inhaled corticosteroids was investigated. Our ECP selection criterion has only little influence on our findings, as we saw a rather homogeneous treatment effect regardless of baseline ECP (Fig. 2). The question arises whether the level of inflammation before treatment is a result of poor compliance. However, the vast majority of the study population had been seen in our outpatient department for years and showed no signs of limited compliance. Moreover, the history and the pulmonary function (20 out of 25 patients with $\mathrm{FEV}_{1} \geq 90 \%$ of predicted) of the patients expressed sufficient clinical stability, so that a run-in phase of $1 \mathrm{wk}$ seemed to be long enough.

Table 2. Outcome variables before and after the 4-wk treatment period and individual changes over the treatment period with placebo or montelukast

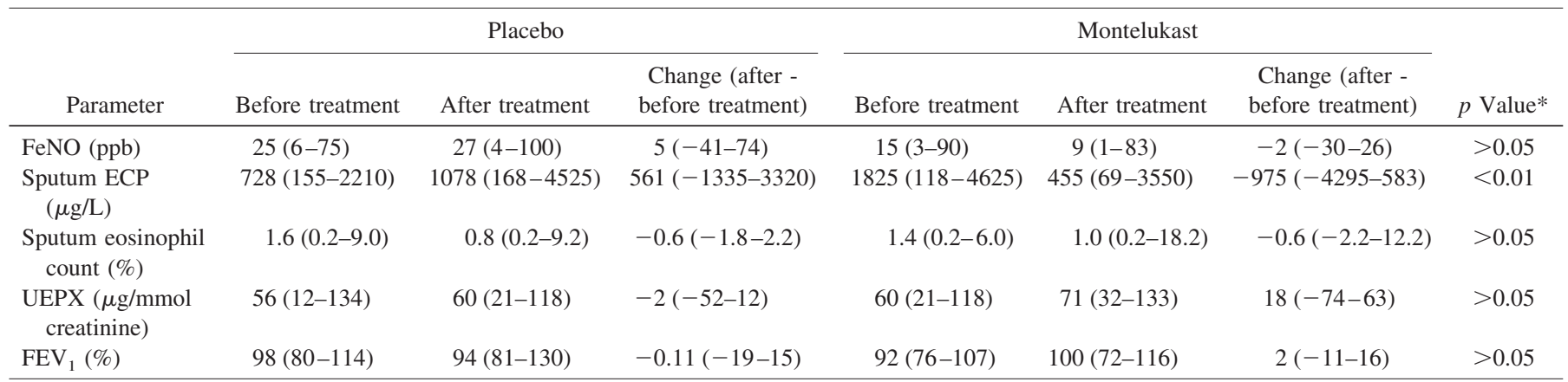

Values given as median (5-95\%) of the indicated parameter.

$* p$ Value for group difference in mean change. 
Table 3. Efficacy end points at baseline, after 4 wk treatment, and changes over the treatment period with placebo or montelukast

\begin{tabular}{|c|c|c|c|c|c|c|c|}
\hline \multirow[b]{2}{*}{ QOL questionnaire* } & \multicolumn{3}{|c|}{ Placebo } & \multicolumn{3}{|c|}{ Montelukast } & \multirow[b]{2}{*}{$p \dagger$ Value } \\
\hline & Before & after & Change & Before & after & Change & \\
\hline Overall QOL & $7.0(6.0-7.0)$ & $7.0(5.0-7.0)$ & $0.0(-1.0-1.0)$ & $7.0(4.0-7.0)$ & $7.0(6.0-7.0)$ & $0.0(0.0-2.0)$ & $<0.05$ \\
\hline Activities & $6.5(5.0-7.0)$ & $7.0(4.0-7.0)$ & $0.0(-1.5-1.5)$ & $6.0(3.5-7.0)$ & $7.0(4.0-7.0)$ & $1.0(-2.0-2.0)$ & $>0.05$ \\
\hline Emotions & $7.0(7.0-7.0)$ & $7.0(6.5-7.0)$ & $0.0(-0.5-0.0)$ & $7.0(4.0-7.0)$ & $7.0(5.0-7.0)$ & $0.0(0.0-1.0)$ & $<0.05$ \\
\hline
\end{tabular}

Values given as median (5-95\%) of the indicated parameter.

* Scores are expressed as the mean score per item.

$\dagger p$ Value for group difference in mean change.

Furthermore, baseline values did not differ significantly between the study groups (Table 2). As eosinophil inflammation in asthmatic patients is associated with an increased expression of the inducible nitric oxide synthase, it is not surprising that our FeNO values are relatively high before treatment. However, after 4 wk of study treatment, only a slight decrease was observed (Table 2). Effects of montelukast on FeNO were studied by Bisgaard et al. (13) in 26 asthmatic children with and without maintenance therapy with inhaled steroids based on a crossover design, and, after $2 \mathrm{wk}$ of $5 \mathrm{mg}$ montelukast once daily, a $20 \%$ reduction in FeNO was observed. The discrepancy with our results on FeNO could be explained, firstly, by a lower statistical power of our study design together with large variation of FeNO before treatment and, secondly, by a potential selection of less treatment-sensitive patients with regard to the regulation of the nitric oxide synthase. The latter could be a consequence of our ECP baseline criterion. Therefore, we emphasize that our results do not rule out an effect of montelukast on FeNO.

In almost all children of the montelukast group, ECP levels decreased within the 4-wk period, whereas no homogenous trend occurred in the placebo group (Fig. 2). Thus, we were able to demonstrate that persisting bronchial inflammation can be found even in clinically stable patients treated with budesonide. Moreover, this persisting eosinophilic inflammation responds well to the addition of montelukast. Ongoing bronchial inflammation can be complicated by an asymptomatic decline of lung function parameters, and, to date, we are aware of neither how much influence chronic bronchial inflammation has on airway remodeling nor when the changes start to become irreversible. Therefore, it seems important to consider a more effective anti-inflammatory treatment at an early stage of childhood asthma (1). Our data point out that montelukast has the potential to reduce persistent eosinophil inflammation and therefore to prevent chronic damage caused by bronchial asthma.

In contrast to sputum ECP, the change in uEPX excretion and sputum eosinophil count did not differ between the groups (Table 2). However, before-treatment uEPX was similar to the level observed earlier in stable asthmatic children (5), and the average eosinophil count was relatively low when compared with studies in adults, with $7.5 \%$ (26) and 9.9\% (11). Thus, in our study, there was little room to move and little improvement possible. Moreover, the add-on effect of montelukast on uEPX excretion and sputum eosinophil count was not the aim of this study. Subjective improvement in daily life is also an important goal of successful anti-asthmatic therapy (1). Clinical benefit is hard to detect when therapy is started under stable conditions. However, the patients receiving montelukast showed a significant elevation in the QOL scores within the domains "emotions" and "overall quality of life score." This might suggest a clinical effect of the add-on treatment with montelukast, which is in agreement with earlier reports from randomized controlled trials on montelukast (14). The negative correlation between ECP and QOL improvements might speak in favor of clinical relevance of ECP as a marker for bronchial inflammation.

To the best of our knowledge, we have shown for the first time that direct measurements of eosinophilic inflammation in the lower airways of children are significantly reduced by the combination of montelukast and budesonide in comparison to budesonide alone. Our data reinforce the fact that LTRA have an anti-inflammatory effect on asthma complementary to inhaled corticosteroids. Furthermore, this study shows that induced sputum analysis can be used in children to quantify their bronchial inflammation and may be a useful tool for monitoring asthma therapy.

Acknowledgments. The authors thank Mrs. Rainer and Mr. Fischer for study assistance.

\section{REFERENCES}

1. National Asthma Education and Prevention Program 1997 Expert Panel Report II: Guidelines for the Diagnosis and Management of Asthma. National Heart. Lung and Blood Institute, National Institutes of Health Publication No. 97-4051. U.S. Department of Health and Human Services, Washington, DC

2. Barnes PJ, Pedersen S 1993 Efficacy and safety of inhaled corticoids in asthma. Am Rev Respir Dis 148:S1-S26

3. Pedersen S 2001 Do inhaled corticosteroids inhibit growth in children? Am J Respir Crit Care Med 164:521-535

4. Cai Y, Carty K, Henry RL, Gibson PG 1998 Persistence of sputum eosinophilia in children with controlled asthma when compared with healthy children. Eur Respir J $11: 848-853$

5. Mattes J, Storm van's Gravesande K, Reining U, Alving K, Ihorst G, Henschen M, Kuehr J 1999 NO in exhaled air is correlated with markers of eosinophilic airway inflammation in corticosteroid-dependent childhood asthma. Eur Respir J 13:13911395

6. Louis R, Lau L, Bron A, Roldaan A, Radermecker M, Djukanovic R 2000 The relationship between airway inflammation and asthma severity. Am J Respir Crit Care Med 161:9-16

7. Jatakanon A, Uasuf C, Maziak W, Lim S, Chung K, Barnes P 1999 Neutrophilic inflammation in severe persistent asthma. Am J Respir Crit Care Med 160:1532-1539

8. Haathela T, Jarvinen M, Kava T, Kiviranta K, Koskinen S, Lehtonen K, Nikander K, Persson T, Selroos O, Sovijarvi A, Stenius-Aarniala B, Svahn T, Tammivaara R, Laitinen LA 1994 Effects of reducing or discontinuing inhaled budesonide in patients with mild asthma. N Engl J Med 331:700-705

9. Calhoun WJ, Lavins BJ, Glass M 1995 Effect of Accolate (zafirlukast) on bronchoalveolar lavage fluid (BAL) after segmental antigen bronchoprovocation in patients with mild to moderate asthma. Am J Respir Crit Care Med 151:A42(abstr)

10. Laitinen LA, Laitinen A, Lindqvist A 1999 Effect of zafirlukast (Accolate) on leukotriene E4 induced airway inflammation in asthma. Am J Respir Crit Care Med 159:A642(abstr)

11. Yoshida S, Ishizaki Y, Shoji T, Onuma K, Nakagawa H, Nakabayashi M, Akahori K, Hasegawa H, Amayasu H 2000 Effect of pranlukast on bronchial inflammation in patients with asthma. Clin Exp Allergy 30:1008-1014 
12. Bratton DL, Lanz MJ, Miyazawa N, White CW, Silkoff PE 1999 Exhaled nitric oxide before and after montelukast sodium therapy in school-age children with chronic asthma: a preliminary study. Pediatr Pulmonol 28:402-407

13. Bisgaard H, Loland L, Anhoj J 1999 NO in exhaled air of asthmatic children is reduced by the leukotriene receptor antagonist montelukast. Am J Respir Crit Care Med 160:1227-1231

14. Simons FE, Villa JR, Lee BW, Teper AM, Lyttle B, Aristizabal G, Laessig W, Schuster A, Perez-Frias J, Sekerel BE, Menten J, Leff JA 2001 Montelukast added to budesonide in children with persistent asthma: a randomized, double-blind, crossover study. J Pediatr 138:694-698

15. Knorr B, Matz J, Bernstein JA, Nguyen H, Seidenberg BC, Reiss TF, Becker A 1998 Montelukast for chronic asthma in 6- to 14-year-old children: a randomized, doubleblind trial. JAMA 279:1181-1186

16. American Thoracic Society 1987 Standards for the diagnosis and care of patients with chronic obstructive pulmonary diseases (COPD) and asthma. Am Rev Respir Dis $136: 225-244$

17. Knorr B, Larson P, Nguyen HH, Holland S, Reiss TF, Chervisnky P, Blake K, van Nispen CH, Noonan G, Freeman A, Haesen R, Michiels N, Rogers JD, Amin RD, Zhao J, Xu X, Seidenberg BC, Gertz BJ, Spielberg S 1999 Montelukast dose selection in 6 to 14-year-olds: comparison of single-dose pharmacokinetics in children and adults. J Clin Pharmacol 39:786-793

18. Juniper EF, Guyatt GH, Feeny DH, Ferrie PJ, Griffith LE, Townsend M 1996 Measuring quality of life in children with asthma. Qual Life Res 5:35-46

19. American Thoracic Society 1987 Standardization of Spirometry. Am Rev Respir Dis 136:1285-1298
20. Zapletal A 1987 Lung function in children and adolescents. In: Herzog H (ed) Progress in Respiration Research. Karger, Basel, pp 137-196

21. Pin I, Gibson PG, Kolendowicz R, Girgis-Gabardo A, Denburg JA, Hargreave FE, Dolovich J 1992 Use of induced sputum cell counts to investigate airway inflammation in asthma. Thorax 47:25-29

22. Apple F, Bandt C, Prosch A, Erlandson G, Holmstrom V, Scholen J, Googins M 1986 Creatinine clearance: enzymatic versus Jaffé determinations of creatinine in plasma and urine. Clin Chem 32:388-390

23. O'Shaughnessy KM, Wellings R, Gillies B, Fuller RW 1993 Differential effects of fluticasone propionate on allergen-evoked bronchoconstriction and increased urinary leukotriene E4 excretion. Am Rev Respir Dis 147:1472-1476

24. Dworski R, Fitzgerald GA, Oates JA, Sheller JR 1994 Effect of oral prednisone on airway inflammatory mediators in atopic asthma. Am J Respir Crit Care Med 149:953-959

25. Reiss TF, Chervinsky P, Dockhorn RJ, Shingo S, Seidenberg B, Edwards TB 1998 Montelukast, a once-daily leukotriene receptor antagonist, in the treatment of chronic asthma: a multicenter, randomized, double-blind trial. Arch Intern Med 158:12131220

26. Pizzichini E, Leff JA, Reiss TF, Hendeles L, Boulet LP, Wei LX, Efthimiadis AE, Zhang J, Hargreave FE 1999 Montelukast reduces airway eosinophilic inflammation in asthma: a randomized, controlled trial. Eur Respir J 14:12-18

27. Pizzichini E, Pizzichini MM, Efthimiadis A, Evans S, Morris MM, Squillace D, Gleich GJ, Dolovich J, Hargraeve FE 1996 Indices of airway inflammation in induced sputum: reproducibility and validity of cell and fluid-phase measurements. Am J Respir Crit Care Med 154:308-317 